\title{
MEDIDAS DA APRENDIZAGEM ORGANIZACIONAL: REVISÃO DE LITERATURA E AGENDA DE PESQUISA
}

\author{
Measurement of organizational learning: literature review and research agenda
}

Edson Oliveira Neves*

Andrea Valéria Steil**

\section{RESUMO}

Este artigo apresenta o estado da arte sobre mensuração da aprendizagem organizacional. Foram utilizadas como referência as escalas publicadas em artigos científicos das bases de dados ISI Web of Science, sub-base Social Sciences Citation Index (SSCI) e Scientific Eletronic Library Online (SciELO). 0 artigo mapeia as escalas de aprendizagem organizacional e analisa as bases conceituais das diferentes medidas existentes. Foram identificadas 32 escalas para mensurar o construto na ISI Web of Science e 3 escalas na SciELO. Essas são provenientes de diferentes domínios e perspectivas conceituais, sendo o domínio mais comum o de processamento de informações e conhecimentos. Os resultados da análise apontam para um cenário de pesquisa embrionário, com ausência de convergência conceitual entre as medidas e fragilidades metodológicas no desenvolvimento de medidas empíricas válidas e confiáveis em aprendizagem organizacional. A partir destes resultados o artigo apresenta uma agenda de pesquisa para o avanço na mensuração da aprendizagem organizacional.

Palavras-chave: Aprendizagem Organizacional. Pesquisas. Mensuração.

\begin{abstract}
This article presents the state of the art on measurement of organizational learning. The scales published in scientific articles in the ISI Web of Science, Social Sciences Citation Index (SSCl) sub-base and the Scientific Electronic Library Online (SciELO) databases were used as reference. The study maps the organizational learning scales and analyzes the conceptual bases of the different measures. We have identified 32 scales to measure the construct in the ISI Web of Science platform and 3 scales in SciELO. These scales belong to different domains and conceptual perspectives, and the most common domain is information and knowledge processing. The results point to a still embryonic research scenario, lack of conceptual convergence between the measures and methodological shortcomings in relation to the development of valid and reliable empirical measurement of organizational learning. From these results, the article presents a research agenda for the advancement in organizational learning measurement.
\end{abstract}

Keywords: Organizational Learning. Research. Measurement.

\footnotetext{
* Doutor em Engenharia e Gestão do Conhecimento pela Universidade Federal de Santa Catarina (UFSC). Professor do Departamento de Ciências Administrativas do Instituto Federal do Norte de Minas Gerais (IFNMG) - Montes Claros (MG), Brasil. E-mail: edson.neves@ifnmg.edu.br. ORCID: 0000-0001-8043-6602

** Doutora em Engenharia de Produção pela Universidade Federal de Santa Catarina (UFSC). Professora do Programa de Pós-graduação em Engenharia e Gestão do Conhecimento e do Programa de Pós-graduação em Psicologia da Universidade Federal de Santa Catarina (UFSC) - Florianópolis (SC), Brasil. E-mail: andreasteil@ egc.ufsc.br. ORCID: 0000-0001-7853-6532
} 


\section{INTRODUÇÃO}

S ão indiscutíveis a importância e a influência da aprendizagem organizacional (AO) no cenário acadêmico-científico e nas práticas de gestão organizacional (ARGOTE; MIRON-SPEKTOR, 2011; ANTONELLO; GODOY, 2011; ALEGRE et al., 2012). Desde que Cyert e March (1963) recorreram à expressão para evidenciar uma perspectiva adaptativa e comportamental da organização, o construto $\mathrm{AO}$ tem atraído grande interesse nos estudos organizacionais. A atratividade da $\mathrm{AO}$ está relacionada à sua associação com o desenvolvimento de competências organizacionais (LE BOTERF, 2002), com os processos que visam manter e melhorar o desempenho organizacional com base no valor da experiência (DIBELLA; NEVIS, 1998), com a renovação estratégica (CROSSAN; LANE; WHITE, 1999), bem como com a adaptação a novas circunstâncias, contextos competitivos e dinâmicos (LIPSHITZ; POPPER; OZ, 1996; FLEURY; FLEURY, 2006).

Apesar desses aspectos, a operacionalização e a mensuração da $A O$ ainda são fontes de controvérsia (TEMPLETON et al., 2004; BAPUJI; CROSSAN; ROUSE, 2005). A ausência de medidas válidas e confiáveis cria barreiras para o desenvolvimento de pesquisas empíricas sobre AO, assim como para sua associação com outros construtos (LYLES; EASTERBY-SMITH, 2003; TAYLOR; TEMPLETON; BAKER, 2010). Também torna difícil avaliar o progresso dos processos de aprendizagem no âmbito organizacional (SPECTOR; DAVIDSEN, 2006), tornando grande parte das pesquisas limitadas à compreensão sobre como se dá este processo e quanto ao seu impacto para indivíduos, grupos e organizações (SINKULA, 1994; BAPUJI; CROSSAN; ROUSE, 2005; BIDO et al., 2011). Esta é uma preocupação relativamente antiga de pesquisadores da área (SLATER; NARVER, 1995; LUKAS; HULT; FERRELL, 1997; TSANG, 1997; LÄHTEENMÄKI; TOIVONEN; MATTILA, 2001; LYLES; EASTERBY-SMITH, 2003), que salientam a necessidade do desenvolvimento de medidas confiáveis e válidas do construto para que esta área do conhecimento avance.

Dado este cenário, o objetivo deste artigo é apresentar o estado da arte da mensuração da $A O$, realizado por meio de uma revisão de literatura. São discutidos como os diferentes domínios e perspectivas de $\mathrm{AO}$ geram formas distintas de interpretar e mensurar o construto. Também são identificadas e apresentadas medidas propostas na literatura, destacando-se os alinhamentos teóricos que fundamentaram o desenvolvimento das mesmas. Além desta seção introdutória, o artigo compreende mais quatro seções. Inicialmente é realizada uma discussão sobre os aspectos teóricos e conceituais da mensuração da AO. Na sequência são apresentados os procedimentos metodológicos, os resultados e a discussão. Por fim apresentam-se propostas para estudos futuros que possam contribuir para o desenvolvimento de um arcabouço teórico cumulativo em relação ao tema.

\section{A MENSURAÇÃO DA APRENDIZAGEM ORGANIZACIONAL}

A atratividade da AO e o ímpeto para se aplicar o conceito ao contexto organizacional motivou o desenvolvimento das primeiras escalas e metodologias para mensuração do construto ainda nas décadas de 1960 e 1970. Entre os métodos clássicos de mensuração da aprendizagem estão, por exemplo, as curvas de experiência (BOSTON CONSULTING 
GROUP, 1968; 1973) e as curvas de aprendizagem (YELLE, 1979; LIEBERMAN, 1987), que não se configuram como escalas, mas, pelo seu potencial para mensurar a aprendizagem, foram utilizadas em muitos estudos. Esta fase inicial foi marcada pela utilização de variáveis proxy para mensuração da AO. Exemplos incluem a idade da organização, a experiência da mesma, o número de patentes e os investimentos em pesquisa e desenvolvimento (JEREZ-GOMÉZ; CÉSPEDES-LORENTE; VALLE-CABRERA, 2005; BAPUJI; CROSSAN; ROUSE, 2005).

A utilização de variáveis proxy para a mensuração da AO tem sido questionada em função de suas limitações metodológicas e teóricas. As críticas apontam para o fato destas medidas não considerarem a complexidade, a multidimensionalidade e os diferentes processos envolvidos na aprendizagem organizacional (HUBER, 1991; GARVIN, 1993, BONTIS; CROSSAN; HULLAND, 2002). Fiol e Lyles (1985) já haviam chamado a atenção para a inconsistência entre a forma como o construto vinha sendo medido e o avanço conceitual no campo da aprendizagem organizacional.

Duas décadas depois, Bapuji, Crossan e Rouse (2005) constataram que as medidas frequentemente usadas para capturar a AO, até 2005, não retratavam a essência do construto como um processo psicossocial em vários níveis, e que os resultados obtidos nestes estudos poderiam não contribuir positivamente para o desenvolvimento de uma teoria de AO. Este posicionamento sugere que muitas pesquisas analisam um fenômeno diferente relacionado à aprendizagem organizacional, uma vez que existem diferentes escolas e escalas para medir aspectos ou dimensões diversas da AO.

Nas duas últimas décadas foram desenvolvidas escalas com maior rigor metodológico e fundamentação teórica mais sólida, no entanto o desenvolvimento de pesquisas empíricas de AO ainda se mostra restrito. O impacto da escassez de medidas válidas e com um aporte teórico consistente e alinhado é um dos fatores comumente relatados na literatura como prejudicial ao desenvolvimento teórico da AO (SOUZA; TREZ, 2006; TAYLOR; TEMPLETON; BAKER, 2010; SANTOS-VIJANDE; LÓPEZ-SÁNCHEZ; TRESPALACIOS, 2012; YU et al., 2013).

As dificuldades enfrentadas pelos pesquisadores para a operacionalização do construto estão relacionadas tanto à complexidade do mesmo, quanto ao ente organizacional (HUBER, 1991; LÄHTEENMÄKI; TOIVONEN; MATTILA, 2001; TEMPLETON et al., 2004; SPECTOR; DAVIDSEN, 2006). A complexidade do construto é evidenciada pela falta de consenso e harmonia conceitual. O campo de definições é vasto e diverso, e se alinha a diferentes matrizes teóricas. Competem inúmeros conceitos em termos de foco, abrangência, operacionalização empírica e relevância prática (MARTíNEZ-LÉON; MARTÍNEZ-GARCÍA, 2011), o que demonstra que a área de AO está em processo de construção (CROSSAN; MAURER; WHITE, 2011). Exemplos incluem o foco da AO em mudanças cognitivas e/ou comportamentais, a perspectiva processual ou de resultado, os níveis de análise individual, grupal, organizacional ou multinível (TSANG, 1997; LÄHTEENMÄKI; TOIVONEN; MATTILA, 2001; LOIOLA; BASTOS, 2003; BIDO et al., 2011).

De forma mais específica, a AO tem sido compreendida como a manifestação da história e das experiências organizacionais em rotinas (HEDBERG, 1981; LEVITT; MARCH, 1988); como um processo de detecção e correção de erros (ARGYRIS; SCHÖN, 1978); como uma combinação de processos que envolve memória organizacional e aquisição, dis- 
tribuição e interpretação de informações (HUBER, 1991); como o potencial da organização agir de forma eficaz (KIM, 1993), dentre outras perspectivas. Essa diversidade conceitual evidencia a presença de diferentes domínios no campo e reflete o caráter multidisciplinar da AO (EASTERBY-SMITH, 1997; MARTÍNEZ-LÉON; MARTÍNEZ-GARCÍA, 2011).

A segunda dificuldade para a operacionalização do construto está relacionada ao ente organizacional. 0 contexto organizacional interfere no processo de aprendizagem, com destaque para o fator humano, para a cultura, para a estrutura e para os processos organizacionais. Ignorar as características do ente organizacional pode resultar em uma visão incompleta e superficial do construto (TAYLOR; TEMPLETON; BAKER, 2010; PICOLI; TAKAHASHI, 2016).

Para Templeton et al (2004), as questões acima levantadas são alguns dos aspectos que tornam a mensuração da AO complexa. Os autores destacam a importância de se observar um roteiro metodológico que oriente o desenvolvimento de medidas válidas e confiáveis. Aspectos que não podem ser negligenciados incluem a adequação da medida a um domínio específico e uma definição sólida e que transmita elementos como o sujeito da aprendizagem, os níveis de análise e as características processuais ou de resultados (HUBER, 1991; LÄHTEENMÄKI; TOIVONEN; MATTILA, 2001; TEMPLETON; LEWIS; SNYDER, 2002, BAPUJI; CROSSAN; ROUSE, 2005).

\section{PROCEDIMENTOS METODOLÓGICOS}

Para mapear o cenário da produção científica sobre mensuração da AO recorreu-se a procedimentos de busca sistemática de literatura. Os seguintes passos foram seguidos: 1) a identificação de uma base de dados que atenda ao interesse de estudo; e 2) a definição dos critérios de busca e dos critérios de inclusão e exclusão de publicações. Este procedimento é similar ao realizado por Crossan e Apaydin (2010) em sua revisão sistemática sobre inovação organizacional, mostrando-se adequado para a identificação, o agrupamento, a sistematização e a análise dos trabalhos desenvolvidos no campo de estudo.

\subsection{DEFINIÇÃO DA BASE DE DADOS}

Elegeu-se como base de dados a ISI Web of Science e sua sub-base Social Science Citation Index (SSCI). A ISI Web of Science possui um dos bancos de dados mais abrangentes na área de Ciências Sociais (CROSSAN; APAYDIN, 2010), apresenta um perfil de produção globalizado e multidisciplinar, com os principais periódicos mundiais indexados. Além disso, disponibiliza ao pesquisador ferramentas tecnológicas para triagem e avaliação de impacto dos trabalhos (SEVINC, 2004; NORRIS; OPPENHEIM, 2007; CHERNYI, 2009).

\subsection{CRITÉRIOS DE BUSCA, INCLUSÃO E EXCLUSÃO DE ARTIGOS}

Foi utilizado no campo Title da base o termo "organizational learning", e, no campo topic, os termos relacionados às métricas ("measure", "scale", "metric", "estimate", 
"survey", "evaluation", "assessment"). O campo topic abrange o título das publicações, as palavras-chaves e o resumo. No campo topic foi utilizado o operador booleano "OR" entre os termos para que, durante o rastreamento, fossem recuperados trabalhos que possuíssem pelo menos uma destas palavras. Com o objetivo de abranger possíveis variações nos termos de busca (plurais, gerúndios, infinitivos, origem), utilizaram-se recursos de truncagem (asterisco e interrogação). Como resultado, chegou-se ao seguinte caminho de busca: Title = "organi?ational learning" AND Topic = "measur*" OR "scale*" OR "metric*" OR "estimat*" OR "survey" OR "evaluat*" OR "assess*".

No processo de busca também se utilizaram filtros: a) tipo de artigos: artigos e revisões; b) delimitação temporal: publicações científicas indexadas até o final do ano de 2015, ou seja, 1945-2015; c) sub-base: SSCI, como já mencionado anteriormente e, d) idioma: inglês. Os dados apresentados neste levantamento foram obtidos em 15 de abril de 2016. As estratégias de busca retornaram um total de 216 publicações. Deste montante, 51 artigos foram desconsiderados por não estarem integralmente disponíveis para download, impossibilitando uma avaliação aprofundada dos mesmos.

Após a leitura dos resumos (e do artigo completo, quando necessário), dos 165 artigos recuperados e disponíveis, 131 foram descartados por não abordarem diretamente a mensuração da aprendizagem organizacional. Nesses artigos, os termos relacionados à métrica e avaliação encontravam-se dissociados do construto, referindo-se a algum outro elemento ou aspecto no contexto de estudo. Também foram descartados os artigos cuja mensuração estava relacionada a outros construtos, como capacidade de aprendizagem organizacional (HULT; FERRELL, 1997; JEREZ-GOMÉZ; CÉSPEDES-LORENTE; VALLE-CABRERA, 2005; CHIVA; ALEGRE; LAPIEDRA, 2007, dentre outros), cultura de aprendizagem (BOREHAM; REEVES, 2008; HUNG et al., 2010), estilos de aprendizagem (BAKER; SINKULA, 2007; WONG; CHEUNG; FAN, 2009; AZADEGAN; DOOLEY, 2010), curvas de aprendizagem (ARTHUR; HUNTLEY, 2005; FIORETTI, 2007), orientação de aprendizagem (SANTOS-VIJANDE et al., 2005; SPICER; SADLER-SMITH, 2006), entre outras.

Como resultado da busca e da aplicação de critérios de inclusão e exclusão chegou-se a 34 artigos. Estes representam toda produção indexada na base Web of Science, no período considerado. Estes trabalhos abordam diretamente o processo de mensuração do construto aprendizagem organizacional, sendo que 32 destes apresentam algum instrumento para avaliar ou medir o construto.

Apesar da Web of Science ser reconhecida por congregar pesquisas de todo o mundo, por possuir uma natureza multidisciplinar, pela abrangência e por ser uma referência em trabalhos de alto fator de impacto na área de aprendizagem organizacional (fatores que motivaram a escolha desta base como foco desta pesquisa), não foram identificados estudos originários do Brasil. Tendo em vista este fato, foi realizado, de forma complementar, um levantamento na base SciELO, área temática a Applied Social Sciences. A base de dados SciELO reúne as principais produções em língua portuguesa e espanhola. Este aspecto permite que se construa um panorama sobre o estudo e o desenvolvimento de escalas no contexto brasileiro.

Seguindo-se os mesmos critérios de inclusão e exclusão aplicados na Web of Science, foram identificados três trabalhos indexados na base SciELO. Estes estudos, assim como os demais estudos recuperados, são apresentados a seguir. 


\section{RESULTADOS: VISÃO GERAL DOS ESTUDOS SOBRE MENSURAÇÃO DE AO}

Os estudos recuperados na base Web of Science são originários de 20 países, com mais de $67 \%$ oriundos da Espanha, China, Taiwan e Estados Unidos, país com o maior volume de publicações sobre o tema ( $20 \%$ do total das publicações). Já quanto aos estudos recuperados na base SciELO, todos têm como origem o Brasil (BIDO et al., 2010; 2011; VERSIANI; ORIBE; REZENDE, 2013).

As pesquisas estão concentradas em um lastro temporal relativamente curto e recente, a partir do ano 2001, sendo que mais da metade dessas publicações ocorreram a partir de 2008. Este fato indica que a pesquisa sobre mensuração da AO se encontra em um estágio embrionário.

As medidas originam-se de alinhamentos teóricos tanto da perspectiva de organizações de aprendizagem como da aprendizagem organizacional, com diferentes propostas conceituais e de operacionalização do construto. 0 construto aprendizagem organizacional também foi utilizado a partir de diferentes domínios. A palavra domínio é compreendida aqui como a perspectiva específica a partir da qual o pesquisador dirige o seu olhar à aprendizagem organizacional. Como ponderam Crossan et al. (1999, p. 522), “[...] domínios dizem respeito a fenômenos diferentes: processamento de informação, inovação de produtos, ou racionalidade limitada". Poucos estudos aprofundaram a investigação dos domínios de AO. Apesar deste aspecto, os 35 trabalhos que apresentam medidas foram agrupados em categorias em função de seu alinhamento teórico e perspectiva conceitual (Quadro 1).

Os domínios de AO estabelecem as bases para a definição do construto, suas dimensões e fatores determinantes. Por conseguinte, as formas de mensurar o construto diferenciam-se grandemente, com variação na qualidade psicométrica de medidas (TAYLOR; TEMPLETON; BAKER, 2010). A existência de diferentes domínios ajuda a explicar a quantidade e a variedade de medidas propostas para mensurar a AO nos trabalhos analisados. Verificou-se, também, que não existe um predomínio de um domínio, uma vez que as medidas tendem a não se repetir, nem serem adaptadas por outros estudos. Este aspecto é verificado mesmo dentro de um único domínio. As escalas identificadas são apresentadas no Quadro 2.

Dos trabalhos recuperados, quatro abordam de forma direta e específica a mensuração da $\mathrm{AO}$, sendo que dois destes apresentam propostas de escalas para mensurar o construto. O foco principal desses estudos é a discussão em torno de metodologias e o desenvolvimento de instrumentos para mensurar a AO (LÄHTEENMÄKI; TOIVONEN; MATTILA, 2001; TEMPLETON; LEWIS; SNYDER, 2002; SPECTOR; DAVIDSEN, 2006 e TEMPLETON et al., 2004). Nesse intuito, os autores destes quatro trabalhos desenvolvem uma análise crítica da literatura, destacando os conflitos conceituais, a complexidade e os desafios no campo e a importância de medidas válidas e confiáveis para se avançar nos estudos de AO.

Todos os demais trabalhos abordam a relação de um determinado construto com a $\mathrm{AO}$ e, para tal, usam escalas específicas. As relações mais exploradas são entre $\mathrm{AO}$ e abordagens tecnológicas, de gestão de informações e conhecimento (CHOU, 2003; DAWES; LEE; MIDGLEY, 2007; LIAO; WU, 2010); AO e inovação (GARCÍA-MORALES; LLORENS- 
-MONTES; VERDÚ-JOVER, 2006; HUNG et al., 2011; WANG; ELLINGER, 2011; YU et al., 2013); e AO e desempenho organizacional (BONTIS; CROSSAN; HULLAND, 2002; REAL; LEAL; ROLDÁN, 2006; JIANG; LI, 2008). Outros temas também são estudados, como a relação entre AO e benchmarking (ASKIM; JOHNSEN; CHRISTOPHERSEN, 2008); a influência da estrutura organizacional sobre a AO (MARTÍNEZ-LÉON; MARTÍNEZ-GARCÍA, 2011); a associação entre AO e estilos de liderança (FRANCO; ALMEIDA, 2011) e entre cultura organizacional e AO (FLORES et al., 2012); dentre outros.

Quadro 1 - Enquadramento dos estudos conforme domínios e perspectivas teóricas de AO.

\begin{tabular}{|c|c|}
\hline Domínios de AO & Pesquisas \\
\hline \multirow{4}{*}{$\begin{array}{l}\text { Renovação organizacional. Aprendizagem } \\
\text { organizacional ocorre por meio de exploração e } \\
\text { explotação (CROSSAN et al. 1999). }\end{array}$} & Lähteenmäki, Toivonen e Mattila (2001) \\
\hline & Bontis, Crossan e Hulland (2002) \\
\hline & Real, Leal e Roldán (2006) \\
\hline & $\begin{array}{l}\text { García-Morales, Llorens-Montes e Verdú-Jover } \\
\text { (2006) }\end{array}$ \\
\hline \multirow{20}{*}{$\begin{array}{l}\text { Aprendizagem organizacional ocorre pelo } \\
\text { processamento de informações e conhecimentos } \\
\text { (HUBER, 1991; TEMPLETON; LEWIS; SNYDER, } \\
\text { 2002). }\end{array}$} & Templeton, Lewis e Snyder (2002) \\
\hline & Panayides (2007) \\
\hline & Dawes, Lee e Midgley (2007) \\
\hline & Askim, Johnsen e Christophersen (2008) \\
\hline & Liao, Fei e Liu (2008) \\
\hline & Hernaus, Škerlavaj e Dimovski (2008) \\
\hline & $\begin{array}{l}\text { Dimovski, Skerlavaj, Kimman e Hernaus } \\
\text { (2008) }\end{array}$ \\
\hline & Schechter (2008) \\
\hline & Sanzo, Santos, García e Trespalacios (2011) \\
\hline & Martínez-León e Martínez-García (2011) \\
\hline & Wang e Ellinger (2011) \\
\hline & $\begin{array}{l}\text { Khakhian, Naeiji, Saeedi e Abbasalizadeh } \\
(2011)\end{array}$ \\
\hline & Aizpurúa, Saldaña e Saldaña (2011) \\
\hline & $\begin{array}{l}\text { Santos-Vijande, López-Sánchez e Trespalacios } \\
\text { (2012) }\end{array}$ \\
\hline & Flores, Zheng, Rau e Thomas (2012) \\
\hline & Yu, Dong, Shen, Khalifa e Hao (2013) \\
\hline & Chouseinoglou, Iren, Karagöz e Bilgen (2013) \\
\hline & Schechter e Atarchi (2014) \\
\hline & Mena e Chabowski (2015) \\
\hline & Versiani, Oribe e Rezende (2013) \\
\hline \multirow{3}{*}{$\begin{array}{l}\text { Aprendizagem organizacional com foco em } \\
\text { tecnologias, inovação e desenvolvimento de } \\
\text { produtos (NONAKA; TAKEUCHI, 1995). }\end{array}$} & Jiang e Li (2008) \\
\hline & Liao e Wu (2010) \\
\hline & Li, Wei, Zhao, Zhang e Liu (2013) \\
\hline
\end{tabular}




\begin{tabular}{|l|l|}
\hline Domínios de AO & Pesquisas \\
\hline \multirow{4}{*}{$\begin{array}{l}\text { Aprendizagem organizacional com foco em } \\
\text { eficácia organizacional, tomada de decisões e } \\
\text { escolhas, orientação das ações da organização } \\
\text { (MARCH; OLSEN, 1975). }\end{array}$} & Kululanga, Price e McCaffer (2002) \\
\cline { 2 - 2 } & Orthner, Cook, Sabah e Rosenfeld (2006) \\
\cline { 2 - 2 } & Hung, Lien, Yang, Wu e Kuo (2011) \\
\cline { 2 - 2 } & $\begin{array}{l}\text { Bido, Godoy, Ferreira, Kenski e Scartezini } \\
(2011)\end{array}$ \\
\cline { 2 - 2 } & Bido, Godoy, Araujo e Louback (2010) \\
\hline \multirow{2}{*}{$\begin{array}{l}\text { Fundamentação teórico-conceitual diversa, com } \\
\text { diferentes correntes. Domínio não específico. }\end{array}$} & Chou (2003) \\
\cline { 2 - 2 } & Wang, Tseng, Yen e Huang (2011) \\
\hline
\end{tabular}

Fonte: Elaborado a partir das concepções de domínios de AO de Crossan, Lane e White (1999), Bontis, Crossan e Hulland (2002), Templeton et al (2004), Cohen e Sproull (1996) e Miller (1996).

Quadro 2 - Escalas utilizadas para mensuração da aprendizagem organizacional.

\begin{tabular}{|c|c|c|c|c|c|}
\hline Ano & Autor(es) & $\begin{array}{l}\text { Principal(is) referên- } \\
\text { cia(s) conceitual(is) } \\
\text { de AO }\end{array}$ & $\begin{array}{c}\text { Escala de } \mathrm{AO} \text { adotada } \\
\text { (e indicadores de } \\
\text { consistência, validade e } \\
\text { confiabilidade) }\end{array}$ & Abordagem & $\begin{array}{l}\text { Nível(is) de } \\
\text { análise }\end{array}$ \\
\hline 2001 & $\begin{array}{l}\text { Lähteenmäki, } \\
\text { Toivonen e } \\
\text { Mattila }\end{array}$ & $\mid \begin{array}{c}\text { Argyris e Schön (1996); } \\
\text { Tannenbaum (1997); } \\
\text { Fiol e Lyles (1985) }\end{array}$ & $\begin{array}{l}\text { Escala composta por } 20 \\
\text { variáveis latentes ( } 75 \\
\text { itens), cujos alfas variam } \\
\text { de } \alpha-0,53 \text { a } \alpha-0,83 \text {. }\end{array}$ & $\begin{array}{c}\text { Apresenta um conjunto de } \\
\text { medidas de } \mathrm{AO} \text {, desenvol- } \\
\text { vidas para verificar se a } \\
\text { aprendizagem organizacional } \\
\text { ocorreu durante o processo } \\
\text { de mudança de cultura } \\
\text { operacional e de negócios de } \\
\text { uma empresa. }\end{array}$ & $\begin{array}{l}\text { Indivíduo; } \\
\text { Organização }\end{array}$ \\
\hline 2002 & $\begin{array}{c}\text { Bontis, Crossan e } \\
\text { Hulland }\end{array}$ & $\begin{array}{c}\text { Crossan, Lane e White } \\
\text { (1999) }\end{array}$ & $\begin{array}{c}\text { Escala composta por } \\
5 \text { variáveis (50 itens). } \\
\text { Menor alfa: } 0,77, \text { maior } \\
\text { alfa: } 0,91 .\end{array}$ & \begin{tabular}{|c|} 
Examina a aprendizagem \\
organizacional a partir dos \\
estoques e fluxos de apren- \\
dizagem entre os diferentes \\
níveis e sua relação com o \\
desempenho organizacional.
\end{tabular} & $\begin{array}{c}\text { Indivíduo; } \\
\text { Grupo; Organi- } \\
\text { zação }\end{array}$ \\
\hline 2002 & $\begin{array}{c}\text { Templeton, Lewis } \\
\text { e Snyder }\end{array}$ & $\begin{array}{c}\text { Autores utilizaram } 78 \\
\text { definições explícitas } \\
\text { de AO. }\end{array}$ & $\begin{array}{l}\text { Escala composta por } \\
8 \text { variáveis e } 28 \text { itens, } \\
\text { sendo que os alfas das } \\
\text { variáveis variam de } \alpha- \\
\quad 0,46 \text { a } \alpha-0,86 .\end{array}$ & $\begin{array}{c}\text { Desenvolve medidas de } \mathrm{AO} \\
\text { a partir de uma abrangente } \\
\text { revisão de literatura. }\end{array}$ & Organizacional \\
\hline 2002 & $\begin{array}{c}\text { Kululanga, Price e } \\
\text { McCaffer }\end{array}$ & $\begin{array}{c}\text { Nonaka (1991); Walsh } \\
\text { e Ungson (1991); } \\
\text { Kim (1993); Wright e } \\
\text { Belcourt (1995); De } \\
\text { Geus (1997); Pedler et } \\
\text { al (1997) }\end{array}$ & $\begin{array}{l}\text { Escala composta por } \\
10 \text { variáveis. Alfa de } \\
\text { Cronbach }(\alpha) \text {, Confiabi- } \\
\text { lidade Composta (CC) e } \\
\text { Variância Média Extraída } \\
\text { (VME) não informados. }\end{array}$ & $\begin{array}{c}\text { Examina a aprendizagem } \\
\text { organizacional na indústria } \\
\text { da construção. }\end{array}$ & $\begin{array}{c}\text { Indivíduo; } \\
\text { Grupo; Organi- } \\
\text { zação }\end{array}$ \\
\hline 2003 & Chou & $\begin{array}{c}\text { Huber (1991); Brown e } \\
\text { Duguid (1991) }\end{array}$ & $\begin{array}{c}\text { Escala composta por } 9 \\
\text { variáveis. Alfa de Cron- } \\
\text { bach para toda a escala: } \\
\alpha-0,9359 .\end{array}$ & \begin{tabular}{|c|} 
Aborda as inter-relações \\
entre os sistemas \\
computacionais, contexto \\
organizacional e aprendiza- \\
gem organizacional.
\end{tabular} & $\begin{array}{l}\text { Indivíduo; } \\
\text { Organização }\end{array}$ \\
\hline
\end{tabular}




\begin{tabular}{|c|c|c|c|c|c|}
\hline Ano & Autor(es) & $\begin{array}{l}\text { Principal(is) referên- } \\
\text { cia(s) conceitual(is) } \\
\text { de AO }\end{array}$ & \begin{tabular}{|c|} 
Escala de $\mathrm{AO}$ adotada \\
(e indicadores de \\
consistência, validade e \\
confiabilidade)
\end{tabular} & Abordagem & $\begin{array}{l}\text { Nível(is) de } \\
\text { análise }\end{array}$ \\
\hline 2006 & $\begin{array}{l}\text { Real, Leal e } \\
\text { Roldán }\end{array}$ & $\begin{array}{c}\text { Crossan, Lane e White } \\
\text { (1999); Bontis, Crossan } \\
\text { e Hulland (2002) }\end{array}$ & \begin{tabular}{|c|} 
Utiliza escala de \\
Bontis, Crossan e Hulland \\
(2002). 5 variáveis \\
(50 itens), cujos alfas \\
variam de $\alpha-0,890$ a \\
$\alpha-0,937$.
\end{tabular} & $\begin{array}{c}\text { Analisa o papel desempe- } \\
\text { nhado pela tecnologia da } \\
\text { informação sobre a aprendi- } \\
\text { zagem organizacional. }\end{array}$ & $\begin{array}{c}\text { Indivíduo; } \\
\text { Grupo; Organi- } \\
\text { zação }\end{array}$ \\
\hline 2006 & $\begin{array}{l}\text { Orthner, Cook, } \\
\text { Sabah e Rosen- } \\
\text { feld }\end{array}$ & $\begin{array}{l}\text { Garvin (1993); Sabah } \\
\text { e Rosenfeld (1999); } \\
\quad \text { Senge (1990) }\end{array}$ & \begin{tabular}{|c|} 
A escala inclui contém 6 \\
variáveis e 18 itens. Os \\
alfas das variáveis variam \\
de $\alpha-0,92$ a $\alpha-0,94$.
\end{tabular} & $\begin{array}{c}\text { A pesquisa avalia o impacto } \\
\text { da AO sobre programas } \\
\text { pós-escolares em Israel e } \\
\text { nos EUA. }\end{array}$ & $\begin{array}{l}\text { Indivíduo; } \\
\text { Organização }\end{array}$ \\
\hline 2006 & $\begin{array}{c}\text { García-Morales, } \\
\text { Llorens-Montes e } \\
\text { Verdú-Jover }\end{array}$ & $\begin{array}{l}\text { Kale et al (2000); } \\
\text { Edmondson (1999); } \\
\text { Wild et al (2002); } \\
\text { Senge et al (1994) }\end{array}$ & \begin{tabular}{|c|} 
Escala elaborada com 2 \\
itens da escala de Kale \\
et al (2000), e 2 itens de \\
Edmondson (1999). Alfa \\
de Cronbach para toda a \\
escala: $0,919$. \\
\end{tabular} & $\begin{array}{c}\text { Analisa uma série de fatores } \\
\text { estratégicos que afetam a } \\
\text { inovação e a aprendizagem } \\
\text { organizacional. }\end{array}$ & $\begin{array}{c}\text { Indivíduo; } \\
\text { Grupo; Organi- } \\
\text { zação }\end{array}$ \\
\hline 2007 & Panayides & $\begin{array}{c}\text { Moorman e Miner } \\
\text { (1998); Sinkula et } \\
\text { al (1997); Sinkula } \\
\text { (1994); Hurley e Hult } \\
\text { (1998) }\end{array}$ & \begin{tabular}{|} 
Utiliza escala desen- \\
volvida por Sinkula \\
et al (1997) e Hult e \\
Ferrell (1997). A escala \\
adaptada é composta por \\
4 variáveis e 15 itens. Os \\
alfas das variáveis variam \\
de $\alpha-0,81$ a $\alpha-0,88$.
\end{tabular} & $\begin{array}{c}\text { Examina os efeitos da } \\
\text { aprendizagem organizacional } \\
\text { sobre a orientação de rela- } \\
\text { cionamento entre empresas, } \\
\text { a eficácia dos serviços de } \\
\text { logística e o desempenho } \\
\text { organizacional. }\end{array}$ & $\begin{array}{l}\text { Organizacional; } \\
\text { Interorganiza- } \\
\text { cional }\end{array}$ \\
\hline 2007 & $\begin{array}{l}\text { Dawes, Lee e } \\
\text { Midgley }\end{array}$ & $\begin{array}{c}\text { Huber (1991); Slater e } \\
\text { Narver (1995) }\end{array}$ & $\begin{array}{c}\text { Escala composta por } 4 \\
\text { variáveis ( } 4 \text { itens). Alfa } \\
\text { de Cronbach para toda a } \\
\text { escala: } 0,78 .\end{array}$ & $\begin{array}{c}\text { Examina como consultores } \\
\text { externos afetam a apren- } \\
\text { dizagem organizacional } \\
\text { no contexto de compra de } \\
\text { produtos complexos de } \mathrm{TI} .\end{array}$ & $\begin{array}{l}\text { Indivíduo; } \\
\text { Organização }\end{array}$ \\
\hline 2008 & $\begin{array}{l}\text { Askim, Johnsen e } \\
\text { Christophersen }\end{array}$ & $\begin{array}{c}\text { Hartley e Allison } \\
\text { (2004); Huber (1991); } \\
\text { Fiol e Lyles (1985); } \\
\text { Dekker e Hansen } \\
\text { (2004) }\end{array}$ & $\begin{array}{c}\text { Escala composta por } 3 \\
\text { variáveis. Alfa, CC e VME } \\
\text { não informados. }\end{array}$ & $\begin{array}{c}\text { Examina a relação entre o } \\
\text { benchmarking dentro de } \\
\text { redes intermunicipais e AO. }\end{array}$ & $\begin{array}{l}\text { Não fica } \\
\text { evidente no } \\
\text { trabalho. }\end{array}$ \\
\hline 2008 & Liao, Fei e Liu & \begin{tabular}{|} 
Argyris e Schon (1978); \\
Baker e Sinkula (1999); \\
Lin (2001)
\end{tabular} & $\begin{array}{c}\text { Escala composta por } \\
3 \text { variáveis e } 17 \text { itens. } \\
\text { Menor alfa: } 0,823, \text { maior } \\
\text { alfa: } 0,882 .\end{array}$ & $\begin{array}{l}\text { Relações entre a inércia } \\
\text { do conhecimento, apren- } \\
\text { dizagem organizacional e } \\
\text { inovação organizacional. }\end{array}$ & $\begin{array}{l}\text { Indivíduo; } \\
\text { Organizaçãa }\end{array}$ \\
\hline 2008 & Jiang e Li & $\begin{array}{c}\text { Miller (1996); Khanna, } \\
\text { Gulati, e Nohria } \\
\text { (1998); Lane e Lubat- } \\
\text { kin (1998) }\end{array}$ & \begin{tabular}{|c|} 
Escala adaptada de \\
Lane, Salk e Lyles \\
(2001) composta por 3 \\
variáveis ( 3 itens). Alfa \\
de Cronbach para toda a \\
escala: $0,85$.
\end{tabular} & \begin{tabular}{|c|} 
Analisa a relação entre $A O$ \\
e desempenho financeiro \\
de empresas no contexto de \\
alianças estratégicas.
\end{tabular} & $\begin{array}{c}\text { Interorganiza- } \\
\text { cional }\end{array}$ \\
\hline 2008 & Schechter & $\begin{array}{l}\text { Lipshitz e Popper } \\
(1998 ; 2000)\end{array}$ & $\begin{array}{c}\text { Escala composta por } 4 \\
\text { variáveis ( } 27 \text { itens), cujos } \\
\text { alfas variam de } \alpha-0,73 \\
\text { a } \alpha-0,91\end{array}$ & $\begin{array}{l}\text { Explora a AO no contexto } \\
\text { escolar por meio de um } \\
\text { framework conceitual de } \\
\text { mecanismos de AO. }\end{array}$ & $\begin{array}{c}\text { Indivíduo; } \\
\text { Grupo; Organi- } \\
\text { zação }\end{array}$ \\
\hline 2008 & $\begin{array}{c}\text { Hernaus, Škerla- } \\
\text { vaj e Dimovski }\end{array}$ & $\begin{array}{c}\text { Huber (1991) Garvin } \\
\text { (1993) }\end{array}$ & $\begin{array}{c}\text { Escala composta por } 4 \\
\text { variáveis (48 itens). Alfa } \\
\text { de Cronbach para toda a } \\
\text { escala: } 0,927 .\end{array}$ & $\begin{array}{c}\text { Verifica a relação entre } \\
\text { aprendizagem organiza- } \\
\text { cional e o desempenho da } \\
\text { empresa. }\end{array}$ & Organizacional \\
\hline
\end{tabular}




\begin{tabular}{|c|c|c|c|c|c|}
\hline Ano & Autor(es) & $\begin{array}{l}\text { Principal(is) referên- } \\
\text { cia(s) conceitual(is) } \\
\text { de AO }\end{array}$ & \begin{tabular}{|c|} 
Escala de $\mathrm{AO}$ adotada \\
(e indicadores de \\
consistência, validade e \\
confiabilidade)
\end{tabular} & Abordagem & $\begin{array}{l}\text { Nível(is) de } \\
\text { análise }\end{array}$ \\
\hline 2008 & $\begin{array}{c}\text { Dimovski, Sker- } \\
\text { lavaj, Kimman e } \\
\text { Hernaus }\end{array}$ & $\begin{array}{l}\text { Daft e Lengel (1986); } \\
\text { Dimovski (1994) } \\
\text { Skerlavaj et al (2007) }\end{array}$ & $\begin{array}{c}\text { Escala composta por } \\
3 \text { variáveis ( } 38 \text { itens). } \\
\text { Alfa, CC e VME não } \\
\text { informados. }\end{array}$ & \begin{tabular}{|c|} 
Análise comparativa \\
cross-cultural do processo de \\
aprendizagem organizacional \\
em empresas da Eslovénia, \\
Croácia e Malásia.
\end{tabular} & Organizacional \\
\hline 2010 & Liao e Wu & $\begin{array}{l}\text { Jerez-Gomez et al } \\
\text { (2005); Ke e Wei } \\
\text { (2006) }\end{array}$ & $\begin{array}{l}\text { Utiliza escala proposta } \\
\text { por Jerez-Gomez et al } \\
\text { (2005). Confiabilidade } \\
\text { composta para toda a } \\
\text { escala: } 0,884\end{array}$ & \begin{tabular}{|c|} 
Analisa a relação entre a \\
gestão do conhecimento, \\
aprendizagem organizacional \\
e inovação organizacional.
\end{tabular} & $\begin{array}{c}\text { Indivíduo; } \\
\text { Grupo; Organi- } \\
\text { zação }\end{array}$ \\
\hline 2010 & $\begin{array}{c}\text { Bido, Godoy, } \\
\text { Araujo e Louback }\end{array}$ & $\begin{array}{c}\text { Chan (2003); Pawlo- } \\
\text { wsky (2001) }\end{array}$ & \begin{tabular}{|c|} 
Utiliza a escala de \\
Chan (2003). Possui 9 \\
variáveis latentes de $1^{\text {a }}$ \\
ordem e 3 de $2^{\text {a }}$ ordem, \\
totalizando 41 itens. São \\
relatados os indicadores \\
de CC e VME.
\end{tabular} & \begin{tabular}{|} 
Examina a relação entre \\
aprendizagem individual, \\
grupal e organizacional em \\
um ambiente industrial.
\end{tabular} & $\begin{array}{c}\text { Indivíduo; } \\
\text { Grupo; Organi- } \\
\text { zação }\end{array}$ \\
\hline 2011 & $\begin{array}{l}\text { Martínez-León e } \\
\text { Martínez-García }\end{array}$ & $\begin{array}{c}\text { Huber (1991); Slater e } \\
\text { Narver (1995) }\end{array}$ & $\begin{array}{l}\text { É utilizada a escala de } \\
\text { AO de Martínez-León e } \\
\text { Martínez (2010) com } \\
5 \text { variáveis (20 itens). } \\
\text { Alfa, CC e VME não } \\
\text { informados. } \\
\end{array}$ & $\begin{array}{c}\text { Analisa se a estrutura orga- } \\
\text { nizacional (especialização, } \\
\text { formalização, autonomia, } \\
\text { centralização e doutrinação) } \\
\text { afeta diretamente o processo } \\
\text { de AO. }\end{array}$ & $\begin{array}{c}\text { Indivíduo; } \\
\text { Grupo; Organi- } \\
\text { zação }\end{array}$ \\
\hline 2011 & $\begin{array}{c}\text { Sanzo, Santos, } \\
\text { García e Trespa- } \\
\text { lacios }\end{array}$ & \begin{tabular}{|} 
Spicer e Sadler-Smith \\
(2006); Jerez-Gomez \\
et al (2005); Tippins \\
e Sohi (2003); Weera- \\
wardena et al (2006)
\end{tabular} & \begin{tabular}{|c} 
Escala adaptada de Spicer \\
e Sadler-Smith (2006) \\
com 7 variáveis (31 \\
itens). Os indicadores de \\
CC das variáveis variam \\
entre 0,858 a 0,946 e os \\
de VME, entre 0,590 a \\
$0,774$.
\end{tabular} & $\begin{array}{c}\text { Analisa as ligações entre AO, } \\
\text { capacidade de marketing } \\
\text { operacional e desempenho } \\
\text { em pequenas e médias } \\
\text { empresas. }\end{array}$ & $\begin{array}{c}\text { Indivíduo; } \\
\text { Grupo; Organi- } \\
\text { zação }\end{array}$ \\
\hline 2011 & Wang e Ellinger & $\begin{array}{c}\text { Dixon (1992); Huber } \\
\text { (1991) }\end{array}$ & $\begin{array}{c}\text { Utiliza a escala de } \\
\text { López et al (2006) com } 4 \\
\text { variáveis ( } 25 \text { itens), cujos } \\
\text { alfas variam de } \alpha-0,846 \\
\text { a } \alpha-0,919 .\end{array}$ & \begin{tabular}{|c|} 
Examina a percepção do \\
ambiente externo como \\
antecedente da AO e a \\
relação desta com o desem- \\
penho em inovação.
\end{tabular} & $\begin{array}{l}\text { Indivíduo; } \\
\text { Organização }\end{array}$ \\
\hline 2011 & $\begin{array}{c}\text { Khakhian, Naeiji, } \\
\text { Saeedi e Abbasa- } \\
\text { lizadeh }\end{array}$ & $\begin{array}{l}\text { Templeton, Lewis e } \\
\text { Snyder (2002) }\end{array}$ & $\begin{array}{c}\text { Utiliza a escala desenvol- } \\
\text { vida por Templeton, Lewis } \\
\text { e Snyder (2002) com } 8 \\
\text { variáveis (28 itens). Alfa } \\
\text { de Cronbach para toda a } \\
\text { escala: } 0,89 .\end{array}$ & $\begin{array}{l}\text { Examina a aprendizagem } \\
\text { organizacional em uma } \\
\text { indústria petroquímica. }\end{array}$ & Organizacional \\
\hline 2011 & Franco e Almeida & $\begin{array}{l}\text { Garvin (1993); Chen } \\
\text { (2005); Senge (1990) }\end{array}$ & $\begin{array}{c}\text { Escala com } 05 \text { variáveis. } \\
\text { Alfa, CC e VME não } \\
\text { informados. }\end{array}$ & \begin{tabular}{|c|} 
Examina a associação entre \\
aprendizagem organizacional \\
e estilos de liderança em \\
organizações de saúde.
\end{tabular} & $\begin{array}{l}\text { Indivíduo; } \\
\text { Organização }\end{array}$ \\
\hline 2011 & $\begin{array}{c}\text { Hung, Lien, Yang, } \\
\text { Wu e Kuo }\end{array}$ & $\begin{array}{c}\text { Argyris e Schön (1996); } \\
\text { Senge (1990); Rhodes } \\
\text { et al (2008); Watkins e } \\
\text { Marsick (2003) }\end{array}$ & \begin{tabular}{|} 
Os autores adotam nesta \\
escala duas variáveis de \\
AO (com 9 itens mensu- \\
ráveis). Indicadores CC: \\
0,82 e $0,85$. Indicadores \\
VME: 0,48 e $0,58$.
\end{tabular} & $\mid \begin{array}{c}\text { Analisa o impacto da Gestão } \\
\text { da Qualidade Total e AO } \\
\text { sobre o desempenho em } \\
\text { inovação da indústria de alta } \\
\text { tecnologia. }\end{array}$ & $\begin{array}{c}\text { Indivíduo; } \\
\text { Grupo; Organi- } \\
\text { zação }\end{array}$ \\
\hline
\end{tabular}




\begin{tabular}{|c|c|c|c|c|c|}
\hline Ano & Autor(es) & $\begin{array}{l}\text { Principal(is) referên- } \\
\text { cia(s) conceitual(is) } \\
\text { de AO }\end{array}$ & $\begin{array}{l}\text { Escala de AO adotada } \\
\text { (e indicadores de } \\
\text { consistência, validade e } \\
\text { confiabilidade) }\end{array}$ & Abordagem & $\begin{array}{l}\text { Nível(is) de } \\
\text { análise }\end{array}$ \\
\hline 2011 & $\begin{array}{c}\text { Wang, Tseng, Yen } \\
\text { e Huang }\end{array}$ & $\begin{array}{c}\text { Lin e Wu (2005) } \\
\text { Crossan, Lane e White } \\
\text { (1999) }\end{array}$ & $\begin{array}{c}\text { Escala com } 4 \text { variáveis ( } 4 \\
\text { itens), sendo o menor alfa } \\
\alpha-0,88 \text { e o maior alfa } \\
\alpha-0,91\end{array}$ & $\begin{array}{c}\text { Analisa a relação entre os } \\
\text { sistemas de avaliação de } \\
\text { desempenho de pessoal em } \\
\text { universidades, } \mathrm{AO} \text { e identifi- } \\
\text { cação organizacional. }\end{array}$ & $\begin{array}{l}\text { Indivíduo; } \\
\text { Organização }\end{array}$ \\
\hline 2011 & $\begin{array}{c}\text { Aizpurúa, Saldaña } \\
\text { e Saldaña }\end{array}$ & $\begin{array}{l}\text { Hult e Ferrell (1997); } \\
\text { Yang et al (2004) }\end{array}$ & $\begin{array}{c}\text { Utiliza a escala de } \\
\text { Palacios-Marques e } \\
\text { Garrigos-Simon (2005). } \\
\text { As variáveis e itens não } \\
\text { são apresentados. A } \\
\text { confiabilidade composta } \\
\text { informada é de } 0,84 \text {. }\end{array}$ & $\begin{array}{c}\text { Examina a relação entre } \mathrm{AO} \\
\text { e o compartilhamento de } \\
\text { conhecimentos na indústria } \\
\text { hoteleira. }\end{array}$ & $\begin{array}{l}\text { Não fica } \\
\text { evidente no } \\
\text { trabalho. }\end{array}$ \\
\hline 2011 & $\begin{array}{c}\text { Bido, Godoy, } \\
\text { Ferreira, Kenski e } \\
\text { Scartezini }\end{array}$ & Chan (2003) & $\begin{array}{c}\text { Escala adaptada de } \\
\text { Chan (2003). Possui } 9 \\
\text { variáveis latentes de } 1^{\mathrm{a}} \\
\text { ordem e } 3 \text { de } 2^{\mathrm{a}} \text { ordem } \\
\text { (26 itens). Indicadores } \\
\text { CC entre } 0,69 \text { e } 0,84 . \\
\text { Indicadores VME entre } \\
0,45 \text { e } 0,68 .\end{array}$ & \begin{tabular}{|} 
Analisa a aprendizagem \\
organizacional em uma \\
instituição financeira a partir \\
do exame da relação entre \\
aprendizagem individual, \\
grupal e organizacional.
\end{tabular} & $\begin{array}{c}\text { Indivíduo; } \\
\text { Grupo; Organi- } \\
\text { zação }\end{array}$ \\
\hline 2012 & \begin{tabular}{|} 
Santos-Vijande, \\
López-Sánchez e \\
Trespalacios
\end{tabular} & $\begin{array}{c}\text { Huber (1991); Slater e } \\
\text { Narver (1995) }\end{array}$ & $\begin{array}{c}\text { Utiliza escala de Lópe- } \\
\text { z-Sánchez et al (2010; } \\
2011) \text { com } 4 \text { variáveis } \\
\text { (32 itens), cujos alfas } \\
\text { variam de } \alpha-0,85 \text { a } \\
\alpha-0,88 .\end{array}$ & $\begin{array}{c}\text { Analisa a relação entre } \mathrm{AO} \text { e } \\
\text { flexibilidade estratégica nas } \\
\text { empresas. }\end{array}$ & $\begin{array}{c}\text { Indivíduo; } \\
\text { Grupo; Organi- } \\
\text { zação }\end{array}$ \\
\hline 2012 & $\begin{array}{l}\text { Flores, Zheng, } \\
\text { Rau e Thomas }\end{array}$ & $\begin{array}{l}\text { Huber (1991); Walsh e } \\
\text { Ungson (1991); Daft e } \\
\text { Weick (1984); Soliman } \\
\text { e Spooner (2000) }\end{array}$ & $\begin{array}{c}\text { Escala com } 5 \text { variáveis } \\
\text { (23 itens). Os alfas } \\
\text { variam de } \alpha-0,69 \text { à } \\
\alpha-0,89 .\end{array}$ & \begin{tabular}{|c|} 
Busca identificar e mensurar \\
os subprocessos de AO e \\
explorar o efeito da cultura \\
organizacional sobre cada \\
um destes subprocessos. \\
\end{tabular} & $\begin{array}{c}\text { Indivíduo; } \\
\text { Grupo; Organi- } \\
\text { zação }\end{array}$ \\
\hline 2013 & \begin{tabular}{|c|} 
Yu, Dong, Shen, \\
Khalifa e Hao
\end{tabular} & $\begin{array}{c}\text { Huber (1991); Tippins } \\
\text { e Sohi (2003) }\end{array}$ & $\begin{array}{c}\text { Escala com } 4 \text { variáveis } \\
\text { (12 itens). Indicadores de } \\
\text { CC variam entre } 0,80 \text { e } \\
0,85 \text { e os indicadores de } \\
\text { VME variam entre } 0,57 \\
\text { e } 0,66 .\end{array}$ & \begin{tabular}{|c|} 
Examina o impacto de \\
fatores como estratégias, \\
adoção de tecnologias e AO \\
para o desenvolvimento da \\
inovação organizacional em \\
economias emergentes.
\end{tabular} & $\begin{array}{c}\text { Indivíduo; } \\
\text { Grupo; Organi- } \\
\text { zação }\end{array}$ \\
\hline 2013 & $\begin{array}{l}\text { Li, Wei, Zhao, } \\
\text { Zhang e Liu }\end{array}$ & $\begin{array}{c}\text { March (1991); Atuahe- } \\
\text { ne-Gima (2005) }\end{array}$ & \begin{tabular}{|c|} 
Os autores trabalham com \\
duas variáveis latentes \\
nesta escala ( 10 itens). \\
Alfas: 0,915 e 0,$838 ;$ \\
indicadores de VME: \\
0,749 e $0,610$.
\end{tabular} & $\begin{array}{c}\text { Explora como as empresas } \\
\text { chinesas de manufatura } \\
\text { promoveram o desempenho } \\
\text { de novos produtos através } \\
\text { da aprendizagem organiza- } \\
\text { cional ambidestra. }\end{array}$ & Organizacional \\
\hline 2013 & $\begin{array}{c}\text { Versiani, Oribe e } \\
\text { Rezende }\end{array}$ & $\begin{array}{l}\text { Templeton, Lewis e } \\
\text { Snyder (2002) }\end{array}$ & $\begin{array}{c}\text { Utiliza escala adaptada } \\
\text { de Templeton, Lewis e } \\
\text { Snyder (2002), sendo } \\
\text { composta por } 8 \text { variáveis } \\
\text { e } 20 \text { itens. Alfa de } \\
\text { Cronbach, CC e VME não } \\
\text { são apresentados. }\end{array}$ & $\begin{array}{l}\text { Examina a contribuição } \\
\text { do método de análise de } \\
\text { solução sistemática de } \\
\text { problemas (Masp) na pro- } \\
\text { moção da aprendizagem } \\
\text { organizacional. }\end{array}$ & Organizacional \\
\hline
\end{tabular}




\begin{tabular}{|c|c|c|c|c|c|}
\hline Ano & Autor(es) & $\begin{array}{l}\text { Principal(is) referên- } \\
\text { cia(s) conceitual(is) } \\
\text { de AO }\end{array}$ & \begin{tabular}{|} 
Escala de $A O$ adotada \\
(e indicadores de \\
consistência, validade e \\
confiabilidade)
\end{tabular} & Abordagem & $\begin{array}{l}\text { Nível(is) de } \\
\text { análise }\end{array}$ \\
\hline 2013 & $\begin{array}{l}\text { Chouseinoglou, } \\
\text { Iren, Karagöz e } \\
\text { Bilgen }\end{array}$ & \begin{tabular}{|c} 
Huber (1991); \\
Dixon (1992); Nevis, \\
DiBella e Gould (1995); \\
Jerez-Gomez, Cespedes- \\
-Lorente e Valle-Cabrera \\
(2005)
\end{tabular} & $\begin{array}{c}\text { Escala composta por } 3 \\
\text { grupos de variáveis (39 } \\
\text { itens). Alfa de Cronbach, } \\
\text { CC e VME não informa- } \\
\text { dos. }\end{array}$ & $\begin{array}{l}\text { Propõe um novo modelo } \\
\text { para avaliar a AO em } \\
\text { organizações de desenvolvi- } \\
\text { mento de software. }\end{array}$ & $\begin{array}{l}\text { Indivíduo; } \\
\text { Grupo; Organi- } \\
\text { zação }\end{array}$ \\
\hline 2014 & $\begin{array}{l}\text { Schechter e } \\
\text { Atarchi }\end{array}$ & $\begin{array}{c}\text { Ellis e Shpilberg } \\
\text { (2003); Lipshitz, } \\
\text { Popper e Friedman } \\
\text { (2002) }\end{array}$ & $\begin{array}{c}\text { Escala adaptada de } \\
\text { Schechter (2008), } \\
\text { composta por } 4 \text { variáveis } \\
\text { (24 itens), cujos alfas } \\
\text { variam entre } 0,71 \text { e } 0,91 .\end{array}$ & $\begin{array}{c}\text { Explora a AO nas escolas } \\
\text { de ensino de nível secun- } \\
\text { dário através do framework } \\
\text { conceitual de mecanismos } \\
\text { de aprendizagem organiza- } \\
\text { cional. }\end{array}$ & $\begin{array}{c}\text { Indivíduo; } \\
\text { Grupo; Organi- } \\
\text { zação }\end{array}$ \\
\hline 2015 & $\begin{array}{c}\text { Mena e Chabo- } \\
\text { wski }\end{array}$ & $\begin{array}{l}\text { March (1991); Miner } \\
\text { e Haunschild (1995); } \\
\text { Kohli et al (1993) }\end{array}$ & \begin{tabular}{|c|} 
Escala composta por 6 \\
variáveis ( 25 itens), sendo \\
que os indicadores de CC \\
variam entre 0,86 e 0,95 \\
e os indicadores de VME \\
entre 0,61 e $0,86$.
\end{tabular} & $\begin{array}{l}\text { O estudo integra a teoria } \\
\text { de marketing e da apren- } \\
\text { dizagem organizacional, } \\
\text { examinando o papel da AO } \\
\text { sobre os stakeholders. }\end{array}$ & $\begin{array}{l}\text { Indivíduo; } \\
\text { Organização }\end{array}$ \\
\hline
\end{tabular}

Fonte: Dados da pesquisa.

As escalas utilizadas nestes estudos guardam poucas semelhanças entre si. No entanto, é perceptível o alinhamento teórico que reflete o domínio ao qual se conecta o estudo (ver Quadro 2). Os estudos que abordam sistemas, tecnologias e gestão de informações possuem uma particularidade. Nestes, as escalas apresentam similaridades ao nível de variáveis ou dimensões (não existe um padrão no uso das terminologias pelos autores), mas não se mantêm ao nível de itens mensuráveis. As variáveis destas escalas remetem ao domínio de Aprendizagem Organizacional como processamento de informações e conhecimentos, e retratam os subprocessos de AO propostos por Huber (1991). Entre as variáveis com este perfil citam-se, por exemplo: aquisição, análise, distribuição, interpretação, armazenamento, recuperação, disseminação, transferência e integração de informações (e/ou conhecimentos).

Em sua maioria, as escalas tratam a AO como um construto multinível. Estão presentes os níveis individual, de grupo, organizacional e, em algumas poucas escalas, o interorganizacional (PANAYIDES, 2007; JIANG; LI, 2008). São exceções as escalas que consideram apenas um nível de análise. Da mesma forma, a visão de AO como um processo é predominante. Em menor número estão as escalas em que as variáveis de mensuração refletem a $\mathrm{AO}$ como um resultado.

No que concerne ao processo de validação das escalas, algumas fragilidades foram identificadas. Entre os trabalhos analisados há estudos que não obedecem a um rigor metodológico para o desenvolvimento das medidas. Em determinados casos, não foram apresentadas as definições constitutiva e operacional que dão sustentação teórica às variáveis propostas, ou não houve uma preocupação em aprofundar sua discussão (KULULANGA; PRICE; MCCAFFER, 2002; DAWES; LEE; MIDGLEY, 2007; ASKIM; JOHNSEN; CHRISTOPHERSEN, 2008; PANAYIDES, 2007; LIAO; FEI; LIU, 2008; WANG et al., 2011). Em outros, os autores mencionam a utilização de escalas de outros autores sem, 
contudo, explicitá-las (GARCÍA-MORALES; LLORENS-MONTES; VERDÚ-JOVER, 2006; AIZPURÚA; SALDAÑA; SALDAÑA, 2011), ou discuti-las, diante de uma nova proposta de estudo (JIANG; LI, 2008; LIAO; WU, 2010).

A análise dos trabalhos também apontou estudos que não explicitam indicadores estatísticos de validade e confiabilidade de suas escalas, como o alfa de cronbach, a confiabilidade composta e a variância média extraída (KULULANGA; PRICE; MCCAFFER, 2002; ASKIM; JOHNSEN; CHRISTOPHERSEN, 2008; DIMOVSKI et al., 2008; MARTÍNEZ-LEÓN; MARTÍNEZ-GARCÍA, 2011; FRANCO; ALMEIDA, 2011; VERSIANI; ORIBE; REZENDE, 2013; CHOUSEINOGLOU et al., 2013). Outra constatação foi a aplicação do conceito de aprendizagem organizacional a outros aspectos da aprendizagem, como a orientação à aprendizagem e à capacidade de aprendizagem organizacional (LIAO; FEI; LIU, 2008; PANAYIDES, 2007). Nestes casos, o conceito de aprendizagem organizacional utilizado (e capturado pelas medidas proclamadas) diverge dos conceitos dos demais trabalhos na área. Esses elementos colocam em risco a validade e a confiabilidade das escalas propostas.

Em suma, a análise dos trabalhos revela falta de convergência entre as medidas adotadas e ausência de alinhamento teórico entre as medidas de aprendizagem organizacional, mesmo no âmbito de um domínio específico. A presença de diferentes interpretações do conceito foi uma das tônicas no conjunto de trabalhos analisados neste estudo que, por sua vez, geraram medidas com características diversas, com pouca ou nenhuma similaridade. Esse panorama denota a necessidade de avanços nas pesquisas sobre a mensuração do construto nos diferentes domínios.

\section{CONSIDERAÇÕES FINAIS}

A literatura tem mostrado que a mensuração se apresenta como uma importante lacuna na pesquisa em aprendizagem organizacional e, nesse sentido, a operacionalização do construto se manifesta como um grande desafio, justamente pelas dificuldades relacionadas à definição de medidas e ao desenvolvimento de instrumentos que permitam a sua avaliação e mensuração. Medidas válidas e confiáveis de AO têm uma grande importância para o campo de estudo tendo em vista a possibilidade que estas trazem para que pesquisas de relevância sejam empreendidas, e muitas outras questões desvendadas (TEMPLETON et al., 2004). No entanto, o que se percebe é que a mensuração do construto continua a ser um grande desafio, mesmo após 50 anos de sua aparição no cenário acadêmico-científico.

Apesar de todos os avanços, muitos pesquisadores ainda apresentam a questão da mensuração como uma das grandes barreiras a serem transpostas a fim de possibilitar avanços na pesquisa em aprendizagem organizacional (LYLES; EASTERBY-SMITH, 2003; BAPUII; CROSSAN; ROUSE, 2005). Diferentes autores observam que a escassez de metodologias apropriadas limita a compreensão do progresso da aprendizagem no âmbito organizacional, assim como seu impacto para indivíduos, grupos e organizações. Relatam, ainda, que os principais fatores que dificultam o desenvolvimento de medidas válidas estão relacionados à própria complexidade dos fenômenos organizacionais, à ausência de um consenso e clareza em torno da definição de aprendizagem organizacional, assim como de uma integração dos estudos e um alinhamento teórico consistente. 
A pesquisa sobre mensuração é essencial para possibilitar avanços científicos nesta área do conhecimento. Parte-se do pressuposto de que, com medidas válidas e confiáveis de aprendizagem organizacional, criam-se as condições metodológicas e instrumentais para 0 desenvolvimento de novos estudos empíricos, para obtenção de respostas a questões ainda em aberto e para o estabelecimento de relações em aprendizagem organizacional.

Por meio do levantamento realizado na base Web of Science, verificou-se a existência de 34 trabalhos que abordam diretamente a mensuração da AO, sendo que 32 apresentam escalas para a mensuração do construto. Estes trabalhos são originários de 20 diferentes países, desenvolvidos por 93 autores e publicados em 27 periódicos. Para o desenvolvimento de suas pesquisas os autores recorreram a um total de 1798 referências bibliográficas.

Por não retornar nenhum trabalho originário do Brasil, foi realizada de forma complementar uma busca na base SciELO, que congrega as principais produções em língua portuguesa e espanhola. Foram identificados apenas 3 trabalhos, publicados nos anos de 2010, 2011 e 2013, que abordam de forma direta o tema mensuração da aprendizagem organizacional e apresentam escalas para avaliação do construto. Este cenário indica que o interesse e a exploração do tema se encontram em um estágio inicial.

Considerando as duas bases consultadas, entre as obras mais citadas estão trabaIhos da matriz teórica de aprendizagem organizacional e de organizações de aprendizagem, o que representa uma tendência da produção científica que aborda os aspectos de medida. Ou seja, possuem uma significativa contribuição destas duas literaturas.

As publicações analisadas abrangem diferentes contextos de pesquisa (negócios, economia empresarial, tecnologia e sistemas de informação, serviços sociais, educação, saúde), com parte dos estudos tratando especificamente da mensuração do construto, e outra parte investigando as relações entre a $\mathrm{AO}$ e outros fenômenos organizacionais em que a mensuração do construto é abordada, mesmo que superficialmente.

Apesar do número de escalas identificadas, não se verificam convergências entre as variáveis adotadas pelos pesquisadores. Dentro de um mesmo domínio e, também, de uma mesma perspectiva teórica - organizações de aprendizagem e aprendizagem organizacional -, concorrem diferentes conceitos e interpretações do construto AO. Como resultado dessa ausência de alinhamento e integração, é restrita a adoção de uma mesma metodologia por diferentes autores. Ou seja, são poucos os trabalhos identificados em que as medidas utilizadas para a AO se repetem ou são adaptadas. Estes aspectos relatados apontam para um campo de estudo ainda pouco explorado no cenário acadêmico-científico. De uma maneira geral, os estudos são muito recentes, uma vez que mais da metade dos trabalhos identificados foram publicados depois de 2008.

Esta pesquisa também identificou fragilidades em alguns estudos no que se refere às propostas de mensuração do construto, como a falta de clareza na explicitação de medidas, a inexistência de definição constitutiva e operacional que lhes dão sustentação teórica, ou mesmo um aprofundamento na discussão destas.

Este trabalho apresentou um panorama geral da produção científica relacionada à mensuração da aprendizagem organizacional. Entretanto, apesar de todo rigor procedimental, cabe destacar suas limitações, como a utilização de apenas duas bases de dados (não 
obstante a abrangência e reconhecimento das mesmas no cenário acadêmico), conseguinte, a possibilidade de não recuperação de alguma pesquisa de relevância. Da mesma forma, a estratégia utilizada para filtragem e recuperação das publicações pode ter omitido outros trabalhos relacionados a esta temática. Desta forma, sugere-se que as futuras pesquisas expandam este mapeamento sobre o assunto para outros bancos de dados, como Scopus, Science Direct, EBSCO, entre outros.

Mesmo com as limitações que uma pesquisa desta natureza pode conter, o estudo traz importantes contribuições para avanços das pesquisas no campo ao disponibilizar aos pesquisadores um amplo quadro informativo que permite uma orientação teórico-epistemológica, assim como a identificação de tendências e gaps para futuras pesquisas. Nesse sentido, apontam-se como sugestões o estudo mais aprofundado da mensuração do construto nos diferentes domínios aqui destacados, a investigação do cenário teórico-conceitual das medidas e fatores que fundamentam os instrumentos já construídos que, por sua vez, podem contribuir para explicar a variabilidade de medidas propostas na literatura e a falta de alinhamento entre estas. O desenvolvimento de estudos fora do eixo EUA-Espanha também parece ser uma proposta relevante e contributiva, especialmente nos países da America Latina e Ásia, economias emergentes e com grande impacto no cenário socioeconômico mundial.

\section{REFERÊNCIAS}

AIZPURÚA, L. I.; SALDAÑA, P. E. Z.; SALDAÑA, A. Z. Learning for sharing: an empirical analysis of organizational learning and knowledge sharing. International Entrepreneurship and Management Journal, v. 7, n. 4, p. 509-518, 2011.

ALEGRE, J. et al. Organisational learning capability, product innovation performance and export intensity. Technology Analysis \& Strategic Management, v. 24, n. 5, p. 511-526, 2012.

ANTONELLO, C. S.; GODOY, A. S. Aprendizagem organizacional no Brasil. Porto Alegre: Bookman, 2011.

ARGOTE, L.; MIRON-SPEKTOR, E. Organizational Learning: From Experience to Knowledge. Organization Science, v. 22, n. 5, p. 1123-1137, 2011.

ARGYRIS, C.; SCHÖN, D. Organizational learning: A theory of action perspective. Addison-Wesley: Reading, 1978.

ARTHUR, J. B.; HUNTLEY, C. L. Ramping up the organizational learning curve: Assessing the impact of deliberate learning on organizational performance under gainsharing. Academy of Management Journal, v. 48, n. 6, p. 1159-1170, 2005.

ASKIM, J.; JOHNSEN, A.; CHRISTOPHERSEN, K. A. Factors behind organizational learning from benchmarking: Experiences from norwegian municipal benchmarking networks. Journal of Public Administration Research and Theory, v. 18, n. 2, p. 297-320, 2008. 
AZADEGAN, A.; DOOLEY, K. Supplier innovativeness, organizational learning styles and manufacturer performance: An empirical assessment. Journal of Operations Management, v. 28, n. 6 , p. $488-505,2010$.

BAKER, W. E.; SINKULA, J. M. Does Market Orientation Facilitate Balanced Innovation Programs? An Organizational Learning Perspective. Journal of Product Innovation Management, v. 24, n. 4, p. 316-334, 2007.

BAKER, W. E.; SINKULA, J. M. The synergistic effort of market orientation and learning orientation on organizational performance. Academy of Marketing Science, v. 27, n. 4, p. 411-427, 1999.

BAPUJI, H.; CROSSAN, M.; ROUSE, M. J. Organizational learning. Methodological and measurement issues. In: INTERNATIONAL CONFERENCE ON ORGANIZATIONAL LEARNING AND KNOWLEDGE, 6th., 2005, Trento, Italy. Proceedings... University of Trento, Italy, v. 6, n. 2, p. 530-543, 2005.

BIDO, D. S. et al. Examinando a relação entre aprendizagem individual, grupal e organizacional em uma instituição financeira. Revista Eletrônica de Administração, v. 17, n. 1, p. 58-85, 2011.

. Articulação entre as aprendizagens individual, grupal e organizacional: um estudo no ambiente industrial. Revista de Administração Mackenzie, v. 11, n. 2, p. 68-95, 2010.

BONTIS, N.; CROSSAN, M. M.; HULLAND, J. Managing an organizational learning system by aligning stocks and flows. Journal of Management Studies, v. 39, n. 4, p. 437-469, 2002.

BOREHAM, N.; REEVES, J. Diagnosing and supporting a culture of organizational learning in Scottish schools. Zeitschrift für Pädagogik, v. 54, n. 5, p. 637-649, 2008.

BOSTON CONSULTING GROUP. Perspectives on experience. Boston: Boston Consulting Group; 1968.

BOSTON CONSULTING GROUP. The experience curve - reviewed IV. The growth share matrix or the product portfolio. BCG Perspectives, n. 135, 1973. Disponível em: http:// www.bcg.com/documents/file13904.pdf. Acesso em: 19 abr. 2016.

CHERNYI, A. The ISI Web of Knowledge, a modern system for the information support of scientific research: a review. Scientific and Technical Information Processing, v. 36, n. 6, p. 351-358, 2009.

CHIVA, R.; ALEGRE, J.; LAPIEDRA, R. Measuring organisational learning capability among the workforce. International Journal of Manpower, v. 28, n. 3-4, p. 224-242, 2007.

CHOUSEINOGLOU, O. et al. AiOLoS: A model for assessing organizational learning in software development organizations. Information and Software Technology, v. 55, p. 1904-1924, 2013.

$\mathrm{CHOU}, \mathrm{S}$. W. Computer systems to facilitating organizational learning: IT and organizational context. Expert Systems with Applications, v. 24, n. 3, p. 273-280, 2003.

COHEN, M.; SPROULL, L. Organizational Learning. London: Sage, 1996. 
CROSSAN, M. M.; APAYDIN, M. A Multi-Dimensional Framework of Organizational Innovation: A Systematic Review of the Literature. Journal of Management Studies, v. 47, n. 6, p. 1154-1191, 2010.

CROSSAN, M. M.; LANE, H. W.; WHITE, R. E. An organizational learning framework: from intuition to institution. Academy of Management Review, v. 24, n. 3, p. 522-537, 1999.

CROSSAN, M. M.; MAURER, C. C.; WHITE, R. E. Reflections on the 2009 AMR Decade Award: Do We Have a Theory of Organizational Learning? Academy of Management Review, v. 36, n. 3, p. 446-460, 2011.

CYERT, R. M.; MARCH, J. G. A behavioral theory of the firm. Englewood Cliffs, New York: Prentice Hall, 1963.

DAFT, R. L.; WEICK, K. A. Toward a model of organizations as interpretation systems. Academy of Management Review, v. 9, p. 284-295, 1984.

DAWES, P. L.; LEE D. Y.; MIDGLEY, D. Organizational learning in high-technology purchase situations: The antecedents an consequences of the participation of external IT consultants. Industrial Marketing Management, v. 36, n. 3, p. 285-299, 2007.

DIBELLA, A. J.; NEVIS, E. C. How organizations learn: An integrated strategy for building learning capability. San Francisco: Jossey-Bass Publishers, 1998.

DIMOVSKI, V. et al. Comparative analysis of the organisational learning process in Slovenia, Croatia, and Malaysia. Expert Systems with Applications, v. 34, n. 4, p. 3063-3070, 2008.

EASTERBY-SMITH, M. Disciplines of organizational learning: contributions and critiques. Human Relations, v. 50, n. 9, p. 1085-1113, 1997.

EDMONDSON, A. Psychological safety and learning behavior in work teams. Administrative Science Quarterly, v. 44, p. 350-383, 1999.

FIOL, M. C.; LYLES, M. A. Organizational learning. Academy of Management Review, v. 10, p. 803-813, 1985.

FIORETTI, G. The Organizational Learning Curve. European Journal of Operational Research, v. 177, p. 1375-1384, 2007.

FLEURY, A; FLEURY, M.T.L. Aprendizagem e Inovação Organizacional: As experiências de Japão, Coréia e Brasil. 2. ed. São Paulo: Atlas, 2006.

FLORES, L.G. et al. Organizational Learning: Subprocess Identification, Construct Validation, and an Empirical Test of Cultural Antecedents. Journal of Management, v. 38, n. 2, p. 640-667, 2012.

FRANCO, M.; ALMEIDA, J. Organisational learning and leadership styles in healthcare organizations: An exploratory case study. Leadership \& Organization Development Journal, v. 32, n. 7-8, p. 782-806, 2011.

GARCÍA-MORALES, V. J.; LLORENS-MONTES, F. J.; VERDÚ-JOVER, A. J. Antecedents and consequences of organizational innovation and organizational learning in entrepreneurship. Industrial Management \& Data Systems, v. 106, n. 1-2, p. 21-42, 2006. 
GARVIN, D. A. Building a Learning Organization. Harvard Business Review, v. 71, n. 4, p. 78-91, 1993.

HUBER, G. P. Organizational learning: The contributing processes and the literatures. Organization Science, v. 2, p. 88-115, 1991.

HULT, G.T.M.; FERRELL, O. C. Global organizational learning capacity in purchasing: Construct and measurement. Journal of Business Research, v. 40, n. 2, p. 97-111, 1997.

HUNG, R. Y. Y. et al. Impact of TQM and organizational learning on innovation performance in the high-tech industry. International Business Review, v. 20, n. 2, p. 213-225, 2011.

. Dynamic capability: Impact of process alignment and organizational learning culture on performance. Journal of World Business, v. 45, n. 3, p. 285-294, 2010.

JEREZ-GOMÉZ, P.; CÉSPEDES-LORENTE, J.; VALLE-CABRERA, R. Organizational learning capability: a proposal of measurement. Journal of Business Research, v. 58, n. 6, p. 715725, 2005.

JIANG, X.; LI, Y. The relationship between organizational learning and firms' financial performance in strategic alliances: A contingency approach. Journal of World Business, v. 43, n. 3, p. 365-379, 2008.

KALE, P. et al. Learning and protection of proprietary assets in strategic alliances: building relational capital. Strategic Management Journal, v. 21, p. 217-317, 2000.

KULULANGA, G. K.; PRICE, A. D. F.; MCCAFFER, R. Empirical investigation of construction contractors' organizational learning. Journal of Construction Engineering and Management - ASCE, v. 128, n. 5, p. 385-391, 2002.

LÄHTEENMÄKI, S.; TOIVONEN, J.; MATTILA, M. Critical aspects of organizational learning research and proposals for its measurement. British Journal of Management, v. 12, p. 113-129, 2001.

LANE, P. J.; SALK, J. E.; LYLES, M. A. Absorptive capacity, learning, and performance in international joint ventures. Strategic Management Journal, v. 22, n. 12, p. 1139-1161, 2001.

LE BOTERF, G. Développer la compétence des professionnels. 4 ed., Paris: Éditions d'Organisation, 2002.

LIAO, S. H.; WU, C. C. System perspective of knowledge management, organizational learning, and organizational innovation. Expert Systems with Applications, v. 37, n. 2, p. 1096-1103, 2010.

LIAO, S. H.; FEI, W. C.; LIU, C. T. Relationships between knowledge inertia, organizational learning and organization innovation. Technovation, v. 28, n. 4, p. 183-195, 2008.

LIEBERMAN, M. The learning curve, diffusion, and competitive strategy. Strategic Management Journal, v. 8, p. 441-452, 1987.

LIPSHITZ, R.; POPPER, M.; OZ, S. Building learning organizations: the design and implementation of organizational learning mechanisms. The Journal of Applied Behavioral Science, v. 32, n. 3, p. 292-305, 1996. 
LOIOLA, E.; BASTOS, A. V. B. A produção acadêmica sobre aprendizagem organizacional no Brasil. RAC - Revista de Administração Contemporânea, v. 7, n. 3, p. 181-201, 2003. LUKAS, B.A.; HULT, M.; FERRELL, O.C. A theoretical perspective of the antecedents and consequences of organizational learning in marketing channels. Journal of Business Research, v. 36, n. 3, p. 233-244, 1997.

LYLES, M.; EASTERBY-SMITH, M. Organizational learning and knowledge management: Agendas for future research. In: LYLES, M.; EASTERBY-SMITH, M (eds.). The Blackwell handbook of organizational learning and knowledge management. Oxford: Blackwell, 2003, p. 637-652.

MARCH, J. G.; OLSEN, J. P. Organizational learning under ambiguity. European Journal of Policy Review, v. 3, n. 2, p. 147-171, 1975.

MARTÍNEZ-LÉON, I. M.; MARTÍNEZ-GARCÍA, J. A. The influence of organizational structure on organizational learning. International Journal of Manpower, v. 32, n. 5-6, p. 537-566, 2011.

MENA, J. A.; CHABOWSKI, B. R. The role of organizational learning in stakeholder marketing. Journal of the Academy of Marketing Science, v. 43, n.4, p. 429-452, 2015.

MILLER, D. A. preliminary typology of organizational learning: Synthesizing the literature. Journal of Management, v.22, n. 3, p. 485-505, 1996.

NORRIS, M.; OPPENHEIM, C. Comparing alternatives to the Web of Science for coverage of the social sciences' literature. Journal of Informetrics, v. 1, n. 2, p. 161-169, 2007.

PANAYIDES, P. M. The impact of organizational learning on relationship orientation, logistics service effectiveness and performance. Industrial Marketing Management, v. 36, n. 1, p. 68-80, 2007.

PICOLI, F. R.; TAKAHASHI, A. Capacidade de Absorção, Aprendizagem Organizacional e Mecanismos de Integração Social. Revista de Administração Contemporânea - RAC, Rio de Janeiro, v. 20, n. 1, p. 1-20, 2016.

REAL, J. C.; LEAL, A.; ROLDÁN, J. L. Information technology as a determinant of organizational learning and technological distinctive competencies. Industrial Marketing Management, v. 35, n. 4, p. 505-521, 2006.

SANTOS-VIJANDE, M. L. et al. Organizational learning and marketing orientation: interface and effects on performance. Industrial Marketing Management, v. 34, p. 187-202, 2005.

SANTOS-VIJANDE, M.L.; LÓPEZ-SÁNCHEZ, J.A.; TRESPALACIOS, J.A. How organizational learning affects a firm's flexibility, competitive strategy, and performance. Journal of Business Research, v. 65, n. 8, p. 1079-1089, 2012.

SCHECHTER, C.; ATARCHI, L. The meaning and measure of organizational learning mechanisms in secondary schools. Educational Administration Quarterly, v. 50, p. 577-609, 2014.

SENGE, P. M. The fifth discipline - The art \& practice of the learning organization. 1. ed. New York, NY: Currency/Doubleday; London: Century Business, 1990. 
SEVINC, A. Web of Science: A unique method of cited reference searching. Journal of the National Medical Association, v. 96, n. 7, p. 980-983, 2004.

SINKULA, J. M. Market information processing and organizational learning. Journal of Marketing, v. 58, n. 1, p. 35-45, 1994.

SLATER, S. F.; NARVER, J. C. Market Orientation and the Learning Organization. Journal of Marketing, v. 59, n. 3, p. 63-74, 1995.

SOUZA, R. V.; TREZ, G. Mensuração em aprendizagem organizacional: adaptação de uma escala para o contexto brasileiro. In: ENCONTRO DA ASSOCIAÇÃO NACIONAL DOS PROGRAMAS DE PÓS-GRADUAÇÃO EM ADMINISTRAÇÃO. 30., 2006, Salvador/BA. Anais ... Salvador: ANPAD, 2006.

SPECTOR, J. M.; DAVIDSEN, P. I. How can organizational learning be modeled and measured? Evaluation and Program Planning, v. 29, n. 1, p. 63-69, 2006.

SPICER, D.P.; SADLER-SMITH, E. Organizational learning in smaller manufacturing firms. International Small Business Journal, v. 24, n. 2, p. 133-158, 2006.

TAYLOR, G.S.; TEMPLETON, G.F.; BAKER, L.T. Factors Influencing the Success of Organizational Learning Implementation: A Policy Facet Perspective. International Journal of Management Reviews, v. 12, n. 4, p. 353-364, 2010.

TEMPLETON, G. F. et al. Methodological and thematic prescription for defining and measuring the Organizational Learning concept. Information Systems Frontiers, v. 6, n. 3, p. 263-276, 2004.

TEMPLETON, G.F.; LEWIS, B.R.; SNYDER, C.A. Development of a measure for the Organizational Learning construct. Journal of Management Information Systems, v. 19, n. 2, p. 175-218, 2002.

TSANG, E. W. K. Organizational Learning and the Learning Organization: a dichotomy between descriptive and prescriptive research. Human Relations, v. 50, n. 10, p. 73-89, 1997.

VERSIANI, A. F; ORIBE, C. Y; REZENDE, S. F. L. A aprendizagem das organizações gerada pelas práticas formais no ambiente de trabalho. Revista de Administração Mackenzie, v. 14, n. 4, p. 15-44, 2013.

WALSH, J. P.; UNGSON, G. R. Organizational memory. Academy of Management Review, v. 16, p. $57-91,1991$.

WANG, H. K. et al. University Staff Performance Evaluation Systems, Organizational Learning, and Organizational Identification in Taiwan. Social Behavior and Personality, v. 39, n. 1, p. 43-54, 2011.

WANG, Y. L.; ELLINGER, A. D. Organizational learning Perception of external environment and innovation performance. International Journal of Manpower, v. 32, n. 5-6, p. 512536, 2011.

WONG, P. S. P.; CHEUNG, S. O.; FAN, K. L. Examining the relationship between organizational learning styles and project performance. Journal of construction Engineering and Management, v. 135, n. 6, p. 497-507, 2009. 
YELLE, L. E. The learning curve: historical review and comprehensive survey. Decision Sciences, v.10, n. 2, p. 302-328, 1979.

YU, Y. et al. Strategies, technologies, and organizational learning for developing organizational innovativeness in emerging economies. Journal of Business Research, v. 66, n. 12, p. 2507-2514, 2013.

Data de Submissão: 27/06/2017.

Data de Aprovação: 20/12/2017. 